\title{
Review
}

\section{The problem of value pluralism. Isaiah Berlin and beyond}

\author{
George Crowder
}

Routledge, New York and London, 2020, x+227pp., ISBN: 978-1-138-

$72482-2$

Contemporary Political Theory (2022) 21, S122-S125. https://doi.org/10.1057/s41296021-00504-x; published online 22 June 2021

George Crowder is an excellent writer who has not only mastered but arguably redefined the topic of value pluralism. Those who suspect that pluralism is an old hat - a relic of the history of ideas in the mid- to late-twentieth century-will be given pause by the refreshing analysis offered in this book. Crowder argues that pluralism is relevant to almost all the main strands of contemporary political theory, including distributive justice, toleration, multiculturalism, agonistic politics, deliberative democracy, and constitutionalism, among others. He also aims to show that the dilemmas of pluralism ignite and fuel the theoretical engines of several prominent schools of political thought today. Crowder traces the importance of value pluralism to Isaiah Berlin, who, he argues, succeeded in launching it as the paradigm within which most of contemporary political theory delivers its insights.

Nowadays, academics in the social sciences and humanities tend to show greater allegiance to pluralism than to liberty. The post-Cold War triumph of liberalism seems to have run its course, and liberty is regarded as implicated in a controversial western-centric system of values. Pluralism, by contrast, promises to embrace meanings and ways of life that transcend European modernity. But Crowder's book shows that the link between liberalism and pluralism is hard to break. In continuity with his previous works, he argues that 'personal autonomy has a special connection with value pluralism' (p. 155). This link between liberty and pluralism is embedded in Berlin's political theory, and it persists in Crowder's. But it is worth noting that Crowder defends a different type of liberalism-one that is hospitable to positive freedom. Unlike Crowder, most scholars who embrace Berlin's pluralism, like John Gray, Bernard Williams, or Chantal Mouffe, distance themselves from liberalism to varying degrees, arguing that this is the inevitable consequence of taking value diversity seriously. They also turn to realist philosophy in trying to free politics from the moral baggage of ideologies and monist doctrines. But although Crowder engages with realist themes of trade-off and compromise, he is 
also very attentive to the moral implications of exercising choice and the consequences of unresolvable clashes of value.

Crowder defines value pluralism in terms of the incommensurability of fundamental values, and he sees monism - that is, theories advancing final truths and ultimate values in an exclusive and single-minded fashion-as its antithesis. The actual 'problem of value pluralism', which is the central subject of the book, consists in the difficulty of prioritising 'the value characteristics of liberalismindividual liberty, equality of opportunity, toleration'-over those espoused, for example, by socialists, conservatives, or fascists. How should we respond to this incommensurability of values?

Crowder tells us that Berlin only sketches answers. Yet his rough outlines turn into highly productive pathways for developing a comprehensive theory of value pluralism capable of delivering vitally needed answers. Crowder identifies three directions of enquiry: appeal to 'the great goods', attention to the context in which the conflict occurs, and conceptual analysis. These provide the grid against which he assesses how other scholars have advanced the value pluralist paradigm. In particular, he explores the contributions of Martha Nussbaum, Jonathan Riley, Stuart Hampshire, John Kekes, Bernard Williams, John Gray, William Galston, Max Weber, Carl Schmitt, Chantal Mouffe, and Christian Welzel, before laying out his own solution to the problem of pluralism.

With regard to the first direction of enquiry, the appeal to the great goods, Crowder argues that only some values are incommensurable. These are 'the great goods', that is, values that are 'authoritative universally' and 'more fundamental and weighty than other goods' (p. 43). For Crowder, this raises two important questions: what could justifiably count as a fundamental value, and what do we do when fundamental values clash? Riley, Hampshire, and Nussbaum provide an answer to the first question: their respective great goods revolve around the themes of social survival, listening to the other side, and 'central capabilities'. But would they accept that their great good is one among many great goods? Nussbaum comes closest to answering in the affirmative when she 'recognises the problem of choice among colliding capabilities'. Yet she would prefer a world where such conflicts are avoided, while a committed value pluralist would not see incommensurability as fundamentally undesirable (p. 61). For Crowder, credible theories of the great goods are important because they rescue pluralism from the charge of relativism. But such theories can only do full service to pluralism if they offer a satisfactory account of how to tackle the conflict of values without undermining value diversity.

Crowder endorses 'a conceptual or logical approach' (p. 116) to resolving the problem of value pluralism. His reflection on the concept of value pluralism reveals commitment to the principle of diversity, or as he puts it, 'pluralist diversity' (p. 143). This principle combines the norm of value multiplicity with aspects of coherence. Multiplicity aims to provide the broadest possible spectrum of values to choose from, while coherence aims to limit this spectrum for the purpose of making 
it fit the specific objectives of a person or community. Crowder's opponents have argued that the feature of coherence seems to go against multiplicity. Why go for multiplicity in the first place, when what really matters is a meaningful way of life based on specific constellations of value? Why invest in a great number of options as opposed to fewer good options? Crowder's answer to the first question is that we cannot know for certain which are the good options. His answer to the second question is that the 'multiplicity element militates against authoritarian political systems that severely narrow the range of goods allowed as legitimate in a society' (p. 121). Things can go wrong in the other direction, too. Without some degree of coherence within a large spectrum of values, we could end up in an environment where the desirable 'minimum unity' in a political framework is lacking, as Crowder observes with regard to the politics of postmodernism or radical multiculturalism. Diversity is promoted best in a liberal egalitarian society.

Pluralists disagree on whether the most important plurality is plurality of values (the great goods), ways of life, or political regimes. Crowder's trademark argument is that the key plurality is that of values: it is at this level that incommensurability occurs and that significant personal choices are made. Pluralism is valuable because it allows individuals to have real access to different great goods and to benefit from a multiplicity of options. Cultures and political regimes that assert a single great good cannot be seen as valuable from a pluralist normative perspective. For example, while Galston defends the Reformation view favouring group toleration, Crowder demonstrates the advantages of the Enlightenment position which emphasises personal autonomy. He argues that personal autonomy is not only at the heart of Enlightenment liberalism, but also that it ultimately enables the toleration of different ways of life in practical terms. This is because the liberal defence of toleration depends on securing the freedom of exit, and such freedom rests on one's capacity to exercise critical judgement and make hard choices, both characteristic of personal autonomy.

However, I would want to question Crowder for ruling out monistic cultures and authoritarian regimes as worthy of being tolerated on value pluralist grounds. First, doing so relies on a problematic distinction of 'values rather than a system of value' (p. 26). Values are compound products, based on adjustments of conflicting demands. The theories of the great goods which Crowder embraces can serve as evidence that forming a vision of what counts as valuable is an outcome of processes of critical refection and of navigating moral dilemmas. If the great goods count as values, then values themselves are systems of value. Second, values are practised in the context of ways of life. They may exist in more abstract forms as ideals, but practising and protecting values depend on the existence of cultures, including traditional and authoritarian ones. Third, incommensurability could also apply to cultures. Cultural conflicts should be approached as mindfully and responsibly as pluralists approach the incommensurability of values. Most importantly, the idea of parity between values suggests that, in certain 
circumstances, we should not judge others. Deeming other peoples' ways of life as morally inferior leads to practices of shaming and marginalisation, against which value pluralism purports to guard.

The two final chapters of the book explore the institutional implications of Crowder's theory by (1) recommending a liberal form of Bellamy's deliberative democracy and (2) pace Waldron, defending judicial review. As a whole, the book offers the most thorough philosophical exploration of value pluralism and champions the institutions of egalitarian liberalism as the only ones capable of upholding pluralist diversity. It is a restatement of liberalism in the era of posttruth, populism, and hyperdemocracy: a liberalism that combines negative freedom as an endorsement of plurality with positive freedom as the capacity to utilise and maintain diverse options through the exercise of autonomy. Crowder's endorsement of personal autonomy does not make his version of liberalism a comprehensive doctrine that embraces only some types of character or systems of moral belief. Personal autonomy and pluralist diversity should be understood as two mutually reinforcing projects which should be fostered in parallel to each other.

Publisher's Note Springer Nature remains neutral with regard to jurisdictional claims in published maps and institutional affiliations.

Maria Dimova-Cookson

Durham University, Durham DH1 3TU, UK maria.dimova-cookson@durham.ac.uk 